\title{
Dependence of DNA-histograms on the sampling techniques in fine needle aspirates of the breast
}

\author{
A. Elzagheid and Y. Collan * \\ Department of Pathology, University of Turku, Kiinamyllynkatu 10, FIN-20520, Turku, Finland
}

Received June 2001

Accepted 30 August 2002

\begin{abstract}
FNAB) samples from 25 breast cancer cases, originally used for cytodiagnosis were subjected to DNA cytometry. There were air dried smears stained with the MGG method, and samples stained with HE or PAP stain after 50\% ethanol fixation and cytocentrifugation. Different sampling strategies were applied. Four methods were tested: method 1: cell groups measured, method 2: all cells measured, method 3: free cells measured, and method 4: atypical free cells measured. Method 4 showed most often DNA aneuploid histogram patterns, sampling method 1 had the highest number of DNA diploid histogram patterns. Diagnostic approaches may benefit from a sampling method detecting the hiding aneuploid cell population. Grading of neoplasm could potentially benefit from other approaches.
\end{abstract}

Keywords: DNA cytometry, breast cancer, fine needle aspiration biopsy, sampling strategies

\section{Introduction}

Quantitation of nuclear DNA content by cytometry has come into practice as an adjunct to diagnosis and grading of malignant tumors $[2,8,9,11,12,15]$, also in association of fine needle aspiration biopsy (FNAB). DNA cytometry could be helpful in confirming the impression of the cytologist and in giving further value to FNAB diagnosis. To be most beneficial, the methods should be applied on the same samples from which the cytological evaluation has been done. We have used this type of diagnostic system and report here our experience on how different sampling practices will affect DNA cytometry histograms in this setting.

\footnotetext{
${ }^{*}$ Corresponding author: Yrjö Collan, M.D., Dr. Med. Sci., FRCPath., Department of Pathology, University of Turku, Kiinamyllynkatu 10, FIN-20520, Turku, Finland. Tel.: +358 2 2613963; Fax: +358 2 613965; E-mail: yrjo.collan@utu.fi.
}

\section{Material and methods}

\subsection{Samples}

There were samples from 25 patients. The number of samples per patient varied between 1 and 5 (Table 1). All samples were originally diagnosed to present cancer. The biopsies were fixed in 50\% ethanol and cytocentrifuged on glass slides to be stained with HE or Papanicolaou stain. In addition, smears were prepared immediately after FNAB, air dried and stained with May-Grünwald-Giemsa stain.

In association with this study different sampling practices of DNA cytometry were compared.

It was also possible to compare the findings after different ways of preparation of the original FNAB.

\subsection{Feulgen staining}

The samples were stained with Feulgen stain according to the Gaub's et al. method [7,13,20]. Before staining the samples were washed in xylene for 3-7 days to remove the cover glass and embedding 
Table 1

\begin{tabular}{lr}
\hline No. of cancer cases & 25 \\
No. of slides & 48 \\
No. of histograms & 192 \\
No. of air dried Giemsa stained smears & 22 \\
No. of ethanol fixed, cytocentrifuged samples & 26 \\
\hline
\end{tabular}

medium. The xylene was removed with ethanol followed by descending (99-50\%) ethanol series. The samples were washed in distilled water, followed by acid hydrolysis in $5 \mathrm{M}$ hydrochloric acid at room temperature $\left(20^{\circ} \mathrm{C}\right)$ for one hour. After washing in distilled water, samples were treated in darkness with Schiff's reagent (stain: pararosaniline) for 2 hours 45 minutes at room temperature $\left(20^{\circ} \mathrm{C}\right)$, rinsed in distilled water, treated for $3 \times 10$ minutes in fresh aqueous sodium tiosulphate $(180 \mathrm{ml}$ distilled water, $10 \mathrm{ml} 1 \mathrm{M} \mathrm{HCl}$, $10 \mathrm{ml} 10 \% \mathrm{Na}_{2} \mathrm{~S}_{2} \mathrm{O}_{5}$ ), and rinsed for 5 minutes. After dehydration the smears were treated with xylene and mounted, then stored in shade.

\subsection{Equipment for image analysis cytometry}

The intensity of Feulgen staining was measured using a computer-assisted image analysis cytometry system with an Olympus BH-2 microscope (Olympus Optical Co., Ltd., Tokyo Japan) utilizing ACAS software (Ahrens Cytometry Analysis System for flow and static cytometry, version 5.02, Olaf Ahrens, Labor für Meßtechnische Beratung und Entwicklung, Bargteheide/Hamburg, Germany), and equipped with electrical current stabilizer. The histograms produced by this software have a resolution of 256 channels. The video camera (Panasonic WV-CD20) had a pickup device of the CCD type with $500 \times 582(291,000)$ pixels. At the objective magnification of $40 \times$ pixel width was $0.261 \mu \mathrm{m}$, and corresponding pixel area $0.068 \mu \mathrm{m}^{2}$. The computer had a video card with $512 \times 1024$ pixels. The measurements were made with a plan objective (S-Plan $40 \times$, numerical aperture 0.30). A stabilized power supply (Laboratory DC power supply model GPS 185, Goodwill Instrument Co., Taiwan) was used for the current supply to the microscope to keep the illumination stable. A 550-nm interference filter (IF 550, Olympus) was used to increase the contrast of the stained nuclei against the background (half value width $550 \mathrm{~nm}+15 /-45$ ). Prior to each measurement session the illumination of the microscope was adjusted according to the method of Köhler. The system was calibrated prior to each session.

\subsection{Sampling alternatives}

In our study, we have 48 samples originally stained by different methods. Some of them were air-dried smears and were stained with the MGG method while the rest was stained with HE stain or PAP stain after $50 \%$ ethanol fixation and cytocentrifugation. We started by testing several types of sampling strategies, and these included the following. 100 nuclei considered to represent cancer were chosen for measurement in addition to 30 small lymphocytes, which acted as internal controls, were set at $2 \mathrm{c}$ and showed a thin peak $(\mathrm{CV} \leqslant 4.2 \%)$. A glare correction $[10,14]$ was made with software of the Ahrens ACAS-programme (Bargteheide/Hamburg, Germany). 4 different sampling methods were applied:

\subsubsection{Sampling method 1}

We selected cells from the cell groups in the sample and produced the DNA histograms from these cells. This method was a selected procedure: all free cells were left outside analysis. In this sampling method there was a risk of nuclear overlaps within cell groups. If there were overlaps the nuclei could not be measured by DNA cytometry.

\subsubsection{Sampling method 2}

Cells in cell groups and free cells between cell groups were measured with equal emphasis. When measuring cell groups nuclear overlaps were avoided. Free cells could usually be measured because overlaps were few. Basically we are here dealing with a random sampling method because all cells were taken for measurement with equal emphasis.

\subsubsection{Sampling method 3}

Only free cells were measured, irrespective of atypia. This is a selected sampling procedure.

\subsubsection{Sampling method 4}

The selection concentrated on finding the most atypical free cells. This method is a highly selective sampling procedure.

\subsection{Interpretation of the histogram}

The diploid region was viewed to be situated within the gate of $1.7-2.3 \mathrm{c}$. A small number $(<10 \%)$ of cells in the tetraploid region (3.4-4.6c) was not considered to represent aneuploidy. When the mode of the peak was completely within the gate of 1.7-2.3c, the peak was defined as diploid. When parts of the cells represented by the peak were outside the gate they 

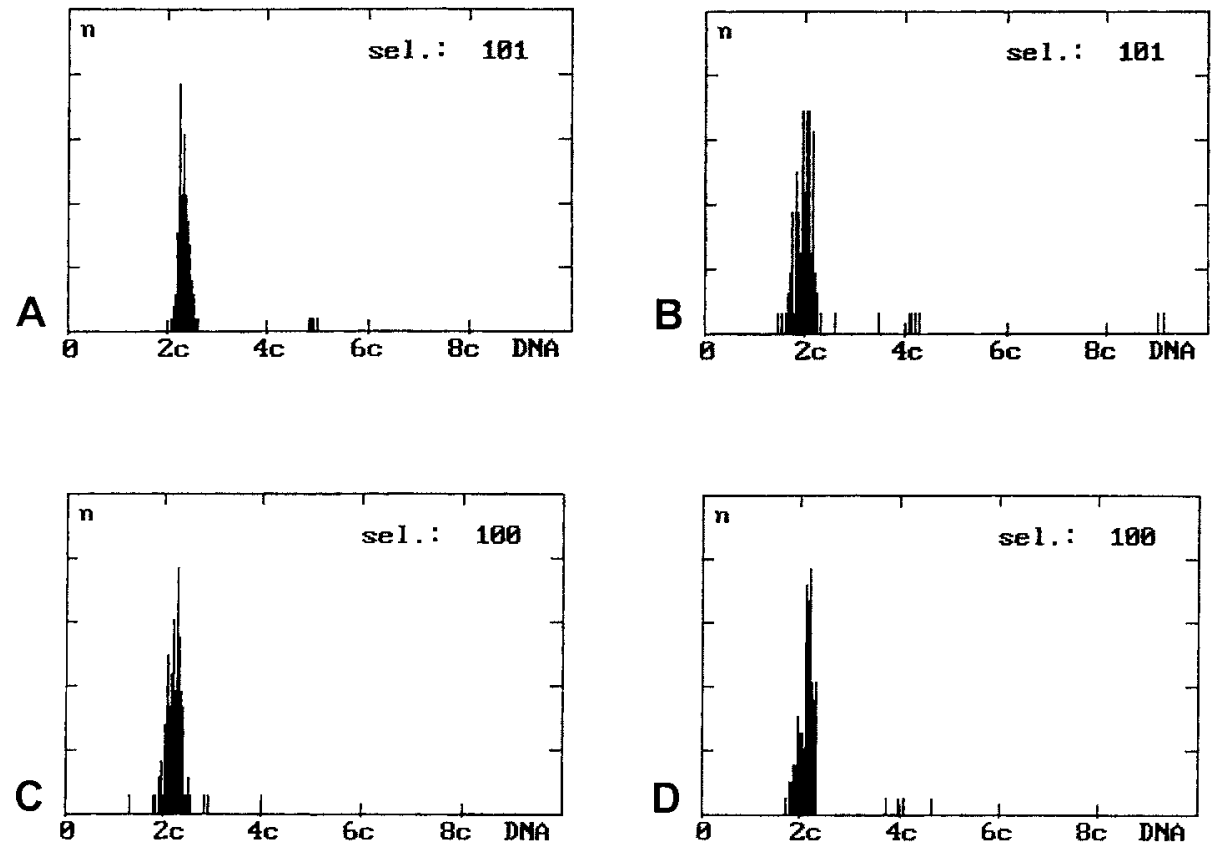

Fig. 1. The use of different sampling methods in a case of diploid breast carcinoma (true smears). 4 sampling methods have been tried. A: Method 1 (cell groups measured). B: Method 2 (all cells measured). C: Method 3 (free cells measured). D: Method 4 (atypical free cells measured). In this case we are dealing with a diploid neoplasm which however contains a few DNA values outside the diploid region (peridiploid cells). Note, however, the few individual potentially aneuploid cells in A, B, C and D. The control lymphocytes showed narrow peaks at $2 \mathrm{c}$ (CV $\leqslant 4.2 \%$ ). In this sample the four sampling methods seem to give practically the same information.

were called peridiploid. When the mode of the peak was outside the defined gate (1.7-2.3c), the peak was called aneuploid. Aneuploid peaks were those with modes outside the above gate and included peaks in the tetraploid region (3.4-4.6c). Individual cells between 2.3-3.4c (without peak) were classified as proliferative cells and individual cells $>5 \mathrm{c}$ were classified as aneuploid cells.

We consider the histograms as identical when the mode of the peaks was located within the gate (A and B in Fig. 2). In non-identical histograms the mode of the peaks was located within different gates (D in Fig. 1 and D in Fig. 2). In this comparison the gates were 1.7$2.3 \mathrm{c}, 2.3-3.4 \mathrm{c}, 3.4-4.6 \mathrm{c}$, and above $4.6 \mathrm{c}$.

\section{Results}

\subsection{Comparison of sampling methods}

The appearance of the histograms in FNAB's of the breast cancer was affected by different sampling methods. The histograms were also influenced by the methods of preparation of the samples (Fig. 4), but not to the degree that conclusions between sampling meth- ods were different in ethanol fixed cytospins or MGGstained smears.

\subsubsection{Comparison of the sampling methods 1 (cell groups) and 2 (all cells)}

Identical histograms were found in 45/48 comparisons in respect to the location of peaks. In addition to differences in the location of peaks there was the general tendency of sampling method 2 to show more aneuploid cells $(>5 \mathrm{c})$ than sampling method 1 . The latter difference was seen in 11/48 samples. Among air dried smear (air dried when freshly prepared from the biopsy material were stained with the MGG stain), the peaks of the histograms were identical in 22/22 samples (Fig. 1). The result suggest that methods 1 and 2 give basically similar histograms irrespective of the original way of preparation of the FNAB (cytospins, MGG smears).

\subsubsection{Comparison of the sampling methods 1 (cell groups) and 3 (free cells)}

These showed identical histogram peaks in 44/48 comparisons. In addition to the differences in the histogram peaks, there was the tendency of sampling method 3 to show more aneuploid cells $(>5 \mathrm{c})$ than the sampling method 1 (16/48 samples) (Fig. 3). Among 

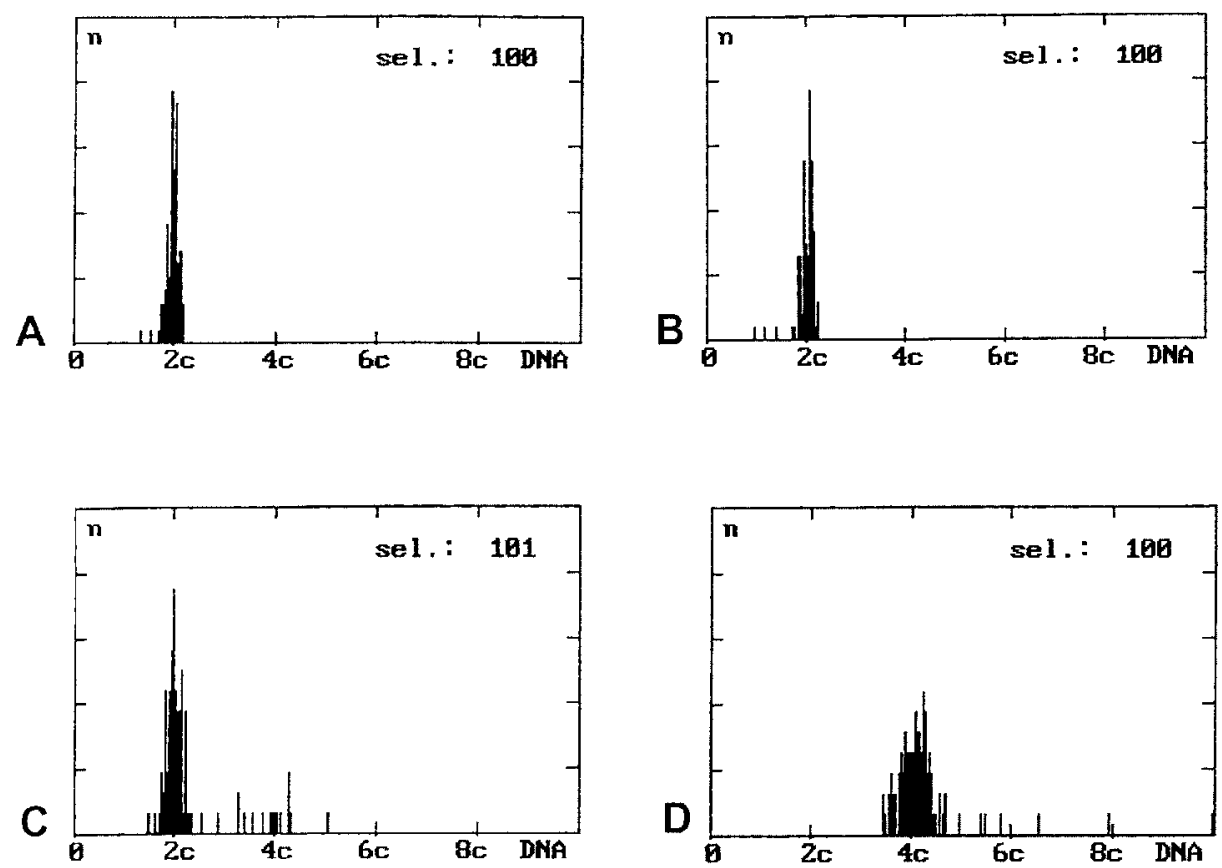

Fig. 2. The use of different sampling methods in a sample originally fixed in 50\% ethanol which appears diploid when cells of cell groups, or all cells of the sample are analysed. A: Method 1 (cell groups measured). B: Method 2 (all cells measured). C: Method 3 (free cells measured). D: Method 4 (atypical free cells measured). In this case method 1 and 2 showed diploid histogram patterns, method 3 included a number of cells at $4 \mathrm{c}$, method 4 showed tetraploid histogram pattern. In all presented histograms control cells were at $2 \mathrm{c}$ and showed a thin peak. In characterization of this neoplasm distinction should be made from the neoplasm presented in Fig. 1 in which all sampling methods showed the diploid pattern. The hiding aneuploid pattern (tetraploidy) could be detected with the sampling method 4 only.

air dried smear, the histogram peaks were identical in 22/22 samples.

\subsubsection{Comparison of the sampling methods 1 (cell groups) and 4 (atypical free cells)}

These showed identical histograms in 11/48 comparisons in respect to the location of the peaks. In addition to the differences in the location of the peaks, there was the tendency of sampling method 4 to show more aneuploid cells $(>5 \mathrm{c})$ than sampling method $1(45 / 48$ samples). Among air dried smear, the histograms were identical in 5/22 samples. 17 samples were different in respect to the histogram peaks. In these 17 the sampling method 4 generally showed higher ploidies than the cells selected by sampling method 1 (Fig. 2).

\subsubsection{Comparison of the sampling methods 2 (all cells) and 3 (free cells)}

These showed identical histograms in 47/48 comparisons. But there was the tendency of sampling method 3 to show more aneuploid cells $(>5 \mathrm{c})$ than sampling method 2 (10/48 samples). Among air dried smear, the histogram peaks were identical in $22 / 22$ samples.

\subsubsection{Comparison of the sampling methods 2 (all cells) and 4 (atypical free cells)}

There were identical histogram peaks in 12/48 comparisons. In addition to differences in the histogram peaks, there was the tendency of sampling method 4 to show more DNA aneuploid histogram patterns (42/48 samples). Among air dried smear, the histograms were identical in 5/22 samples. 17 samples were different in respect to the histogram peaks and in these 17 the sampling method 4 (atypical free cells) generally showed higher DNA aneuploid histogram patterns than the sampling method 2 .

\subsubsection{Comparison of the sampling methods 3 (free cells) and 4 (atypical free cells)}

These showed identical histogram peaks in 12/48 comparisons. In addition to the differences in the histogram peaks, there was tendency of sampling method 4 to show more aneuploid cells $(>5 \mathrm{c})$ than sampling method 3 (42/48 samples). Among air dried smear, the histograms were identical in $5 / 22$ samples. 17 samples were different in respect to the histogram peaks. In these 17, the sampling method 4 showed more aneuploid cells than the sampling method 3 . 

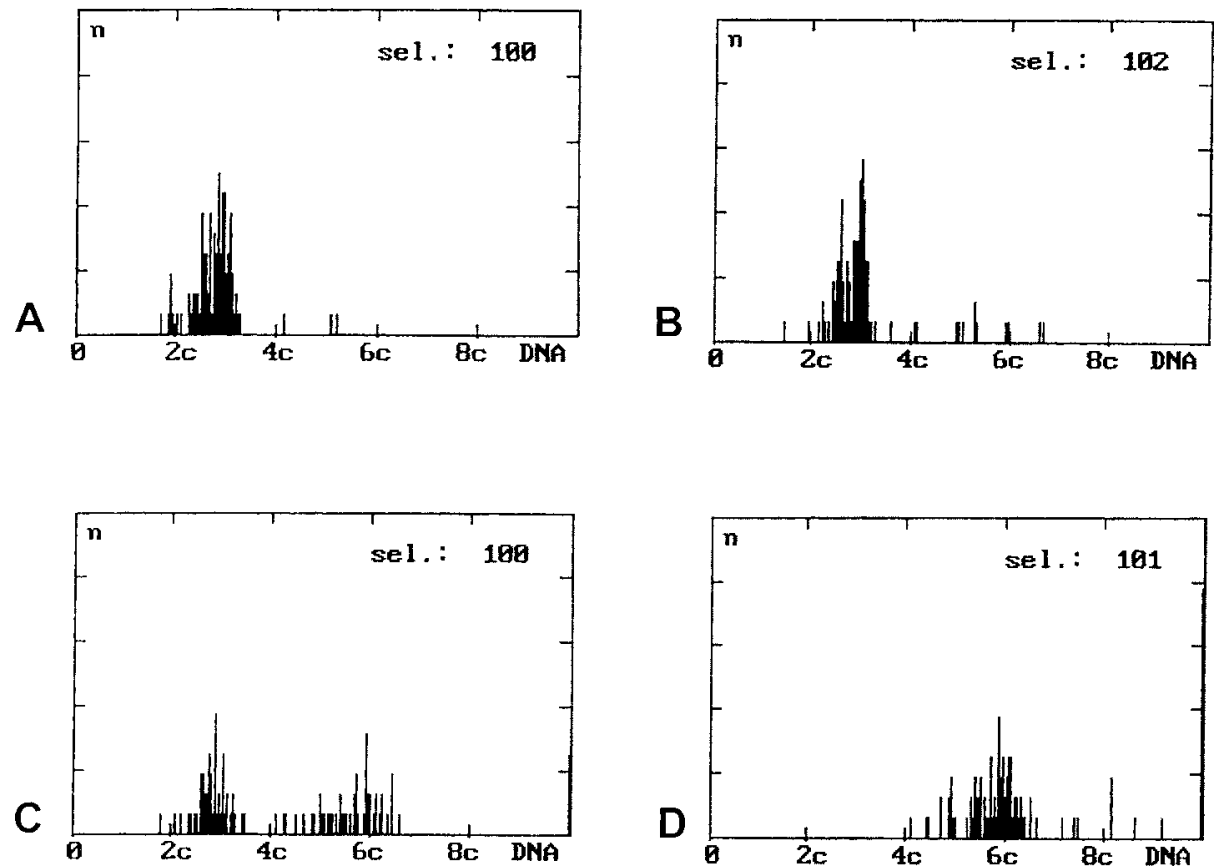

Fig. 3. The use of different sampling methods in an aneuploid sample originally fixed in $50 \%$ ethanol. A: Method 1 (cell groups measured). B: Method 2 (all cells measured). C: Method 3 (free cells measured). D: Method 4 (atypical free cells measured). There are basically two main clones of aneuploid cells: cells having DNA content roughly between 2.2-3.1, and cells with DNA content dominantly between 5.0-6.6. The latter group of cells corresponds to a cell population produced by cell cycle activation from the former. There are also DNA values outside the above limits demonstrating the instability of the mitotic genome. The highest abnormal DNA values are to be found with the sampling method 4 . In this case all sampling methods revealed aneuploidy. The histogram patterns still appeared different, however.

The sampling method 4 (atypical free cells) showed the most aneuploid histogram patterns followed by sampling method 3 (free cells). Sampling method 2 (all cells) tended to produce histograms which looked more euploid than sampling methods 3 and 4. Sampling method 1 (cell groups) showed the least abnormal pattern.

\subsection{Comparison of DNA cytometry after different sample preparation methods}

The histograms of samples originally fixed in $50 \%$ ethanol were not necessarily perfectly similar with histograms from samples originally stained as air dried smears. However, no consistent pattern could be detected (Fig. 4). Comparison suggested that the differences were biggest when the sampling method 4 was used, possibly suggesting the presence of difficulties in characterization and selection of "atypical free cells".

\section{Discussion}

Our study shows that the DNA analysis is possible from FNAB samples which have been already stud- ied for cytodiagnosis. Only occasionally there might be difficulties in the destaining of May-GrünwaldGiemsa stained smears taking place during the hydrolysis. Samples stained with the PAP stain or H\&E always seem to give consistent results. The findings of the DNA analysis presented in the DNA histogram can support histological diagnosis and also include an aspect of prognostication as shown by Auer et al. [1] and Böcking et al. [6].

Our results on the various ways of sampling, however, show that different ways of sampling should be considered when DNA histograms from FNABs are produced. This is in line with the finding of Buhmeida et al. [7] on prostate cancer. As in Buhmeida's study, also in our study the most atypical DNA histogram patterns are to be found among free cancer cells, and not among the cells of cell groups. Because this type of information has not been available earlier, the study suggests further prognostic studies in which the application of the available prognostic methods $[1,6,11,16-$ 19 ] could be tested on the histograms produced by different sampling methods in breast cancer.

The use of several sampling methods may sound too laborious. However, it seems to us at the moment that 

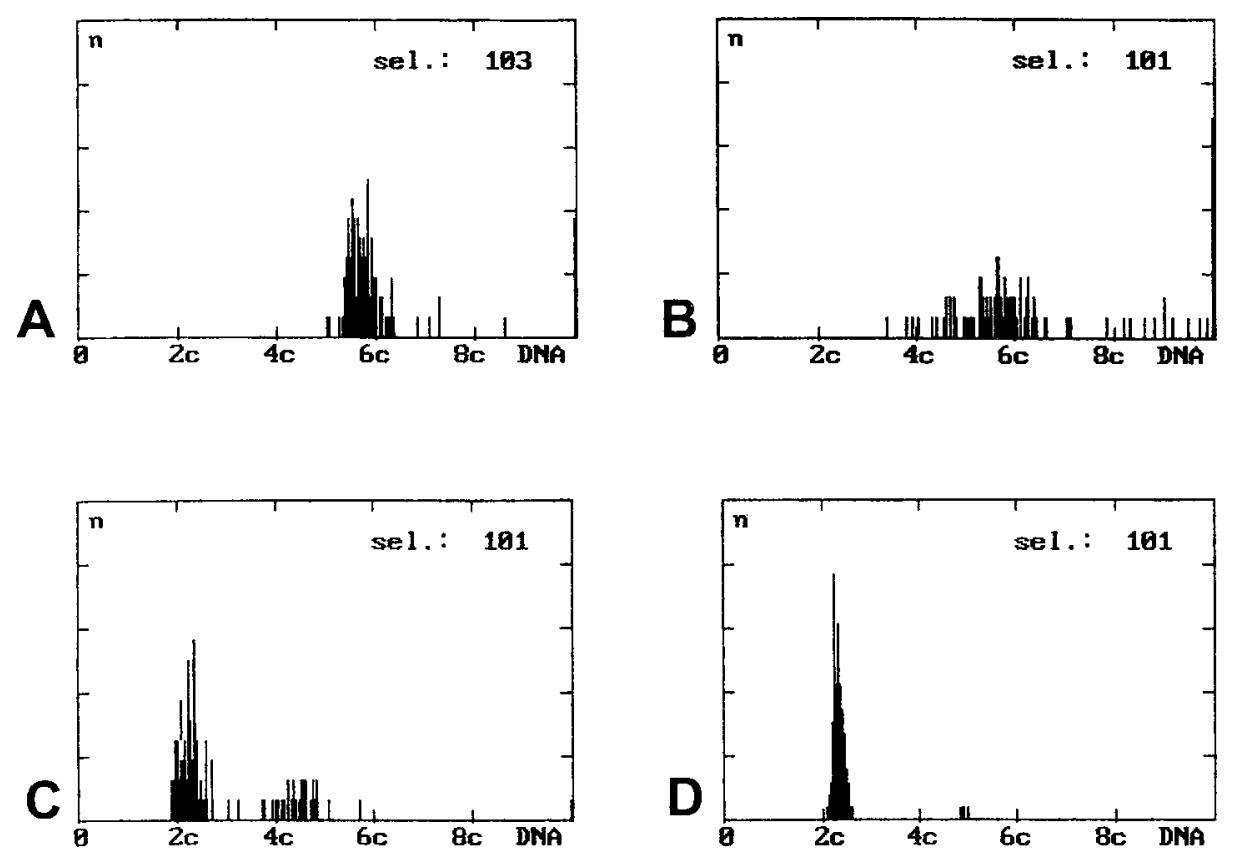

Fig. 4. The use of different preparation methods do not necessarily give perfectly similar histograms. A, Sample originally fixed in $50 \%$ ethanol. B, The sample originally stained as a smear. In A and B sampling method 4 is used. Both preparation methods have detected aneuploidy. In C and D sampling method 1 from same patient. C, Sample originally fixed in 50\% ethanol. D, Sample originally stained as true smear. In this comparison cytocentrifuged cells are more in favor of aneuploidy.

the use of methods 2 (all cancer cells) and 4 (atypical free cells) will give more thorough general impression about the DNA distribution in breast cancer samples than method 2 (all cancer cells) alone. However, additional studies will be necessary in this evaluation.

A selective sampling for rare atypical nuclei no doubt will be able to increase the diagnostic sensitivity for cancer [15], as confirmed by this study.

Simple and complex algorithms or classification strategies for histogram interpretation $[1,3,4,6]$ may be used for three purposes, depending on the material under investigation and the diagnostic or clinical questions: for diagnosis of neoplasia, prognostication of neoplasia, and therapy planning of neoplasia (ESACP consensus) [5]. Testing the value of these different interpretation options of the histogram, in association with different types of sampling is urgent and may give further support to differential diagnosis and prognostication after FNAB.

Our finding no doubt may have therapeutic consequences. However, combining the DNA histogram features and sampling methods with the follow-up of the patients will be necessary before the clinical relevance of findings can be proven. It is clear, however, that if non-diploidy is considered as a reliable sign of malignant or suspect cases, sampling based on atypical free cells will find a higher number of patients for therapy than cell group based analysis.

We are progressing toward studies on benign breast disease including fibroadenoma to prove that selection of free cells in benign lesions will result in consistently diploid DNA histograms. From the biological point of view, it may be that cells which are in DNA synthesis heading towards mitosis are often presented as the free cells. How often this may happen is unknown. From the diagnostic angle it will be important to make a distinction between cells which are heading towards mitosis, and between cells which have passed mitosis, or have failed to produce a traditional mitosis and so have been able to multiply their DNA without proper nuclear or cell division. Anyhow, it seems that more attention should be paid to atypical free cells in FNAB samples during the measurement by DNA cytometry to detect abnormality at highest efficiency.

\section{References}

[1] G.U. Auer, T.O. Caspersson and A.S. Wallgren, DNA content and survival in mammary carcinoma, Analyt. Quant. Cytol. 2 (1980), 161-165. 
[2] H. Beerman, P.M. Kluin, C.J.H. Van de Velde and C.J. Cornelisse, Prognostic significance of DNA-ploidy in a series of 690 primary breast cancer patients, Int. J. Cancer 45 (1990), 34-39.

[3] A. Böcking, C.P. Adler, H.H. Common, B. Granzen and W. Auffermann, Algorithm for DNA-cytophotometric diagnosis and grading of malignancy, Analyt. Quant. Cytol. 6 (1984), $1-8$.

[4] A. Böcking, R. Chatelain, M. Homge, R. Daniel, A. Gillissen and D. Wohltmann, Representativity and reproducibility of DNA malignancy grading in different carcinomas, Analyt. Quant. Cytol. 11 (1989), 81-86.

[5] A. Böcking, F. Giroud and A. Reith, Consensus report of the ESACP task force on standardization of image cytometry, $A n$ alyt. Cell. Pathol. 8 (1995), 67-74.

[6] A. Böcking, R. Chatelain, S. Biesterfeld, E. Noll, D. Biesterfeld, D. Wohltmann, D. Math and C. Goeck, DNA-grading of malignancy in breast cancer. Prognostic validity, reproducibility and comparison with other classifications, Analyt. Quant. Cytol. 11 (1989), 73-80.

[7] A. Buhmeida, T. Kuopio and Y. Collan, Influence of sampling practices on the appearance of DNA image histograms of prostate cells in FNAB samples, Analyt. Cell. Pathol. 18 (1999), 95-102.

[8] G.M. Clarke, L.G. Dressler, M.A. Owens, G. Pounds, T. Oldaker and W.L. McGuire, Prediction of relapse or survival in patients with node-negative breast cancer by DNA flow cytometry, N. Engl. J. Med. 320 (1989), 627-633.

[9] C.J. Cornelisse, C.J. Van de Velde, R.J.C. Caspers, A.J. Moolenaar and J. Hermans, DNA ploidy and survival in breast cancer patients, Cytometry 8 (1987), 225-234.

[10] D.A. Diamond, S.F. Berry, H.J. Eggleston and D.S. Coffey, A new method to assess metastatic potential of human prostate cancer: relative nuclear roundness, J. Urol. 128 (1982), 729 734.

[11] A.G. Fallenius, G.U. Auer and J.M. Carstensen, Prognostic significance of DNA measurements in 409 consecutive breast cancer patients, Cancer 62 (1988), 331-341.
[12] A.G. Fallenius, S.A. Franzen and G.U. Auer, Predictive value of nuclear DNA content in breast cancer in relation to clinical and morphologic factors. A retrospective study of 227 consecutive cases, Cancer 62 (1988), 521-530.

[13] J. Gaub, G.U. Auer and A. Zetterberg, Quantitive cytological aspects of a combined Feulgen naphthol yellow $\mathrm{S}$ staining procedure for the simultaneous determinations of nuclear and cytoplasmic protein and DNA in mammalian cells, Exp. Cell. Res. 92 (1975), 323-332.

[14] D.J. Goldstein, Aspect of scanning microdensitometry. I. Stray light (glare), J. Microsc. 92 (1970), 1-16.

[15] G. Haroske, F. Giroud, A. Reith and A. Böcking, Part I: Basic consideration and recommendations for preparation, measurement and interpretation, Analyt. Cell. Path. 17 (1998), 189200.

[16] O.P. Kallioniemi, G. Blanco, M. Alavaikko, T. Hietanen, J. Mattila, K. Lauslahti and T. Koivula, Tumour DNA ploidy as an independent prognostic factor in breast cancer, Br. J. Cancer 56(5) (1987), 637-642.

[17] O.P. Kallioniemi, G. Blanco, M. Alavaikko, T. Hietanen, J. Mattila, K. Lauslahti, M. Lehtinen and T. Koivula, Improving the prognostic value of DNA flow cytometry in breast cancer by combining DNA index and S-phase fraction, Cancer $\mathbf{6 2}$ (1988), 2183-2190.

[18] O.P. Kallioniemi, T. Hietanen, J. Mattila, M. Lehtinen, K. Lauslahti and T. Koivula, Aneuploid DNA content and high S-phase fraction of tumour cells are related to poor prognosis in patients with primary breast cancer, Eur. J. Cancer Clin. Oncol. 23(3) (1987), 277-282.

[19] A. Longin, B. Fontanière, V. Pinzani, G. Catimel, C. Souchier, M. Clavel and F. Chauvin, An image cytometric DNA-analysis in breast neoplasms parameters of DNA-aneuploidy and their relationship with conventional prognostic factors, Pathol. Res. Pract. 188 (1992), 466-472.

[20] L. Talve, Y. Collan and T. Ekfors, Primary malignant melanoma of the skin. Relationships of nuclear DNA content, nuclear morphometric variables, Clark level and tumor thickness, Analyt. Quant. Cytol. Histol. 19 (1997), 62-74. 


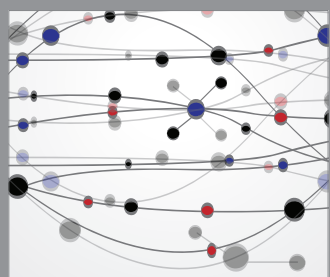

The Scientific World Journal
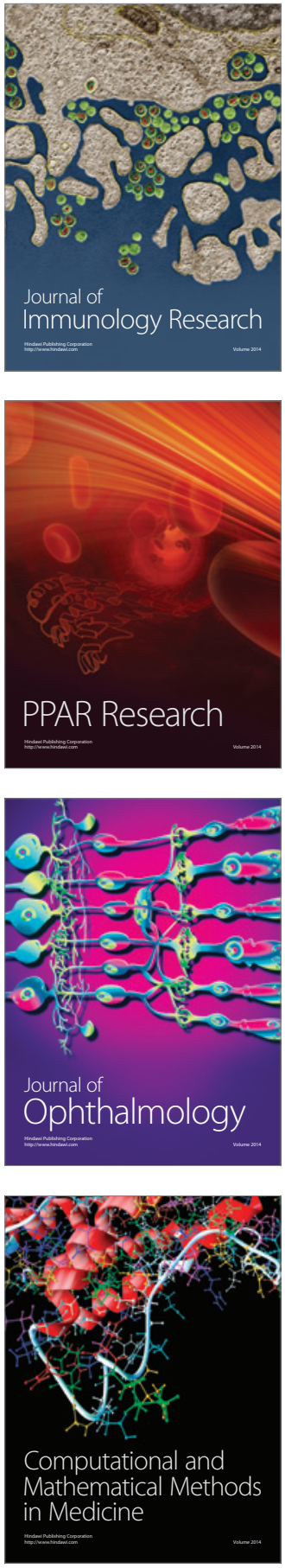

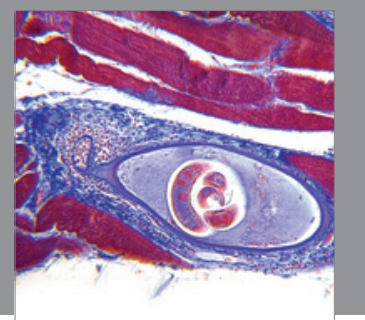

Gastroenterology

Research and Practice
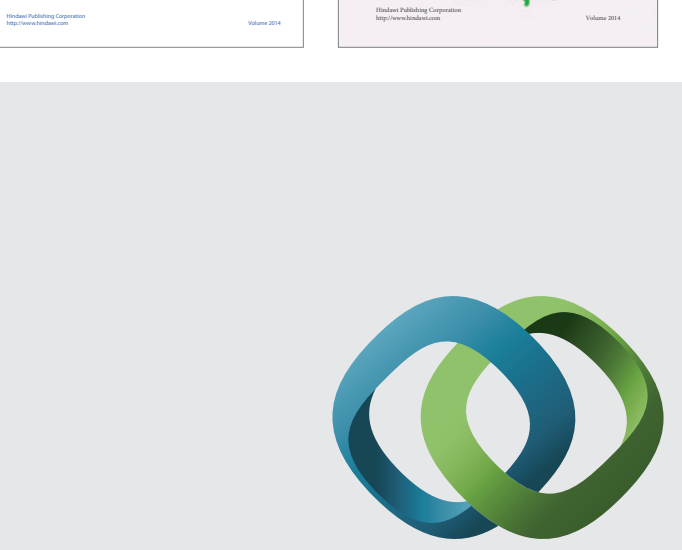

\section{Hindawi}

Submit your manuscripts at

http://www.hindawi.com
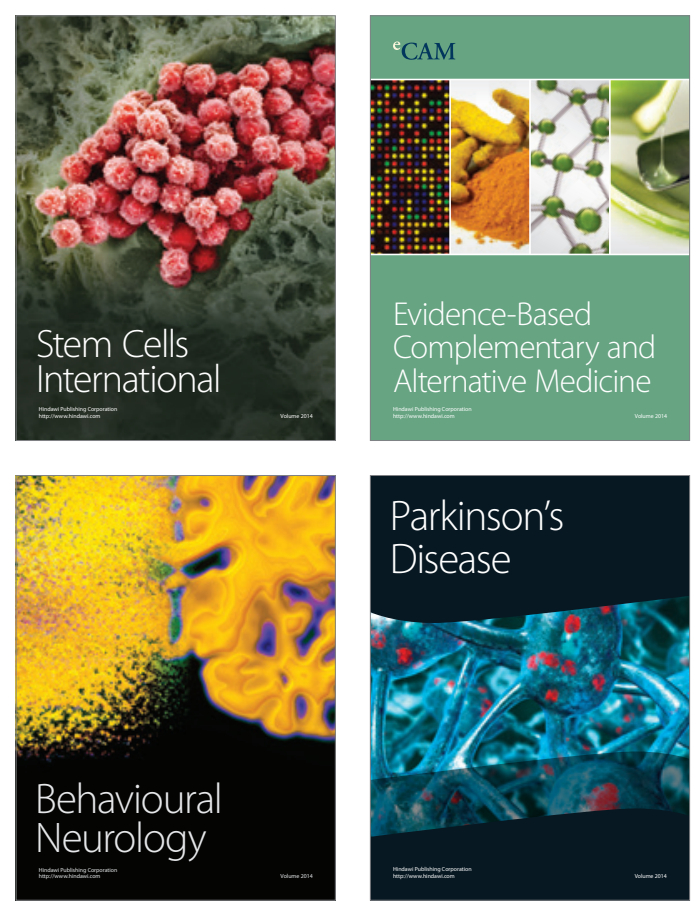

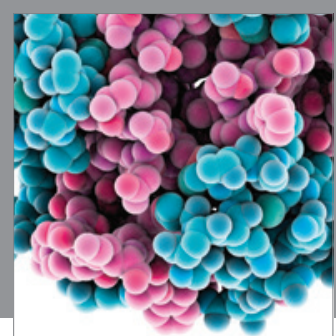

Journal of
Diabetes Research

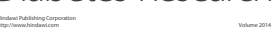

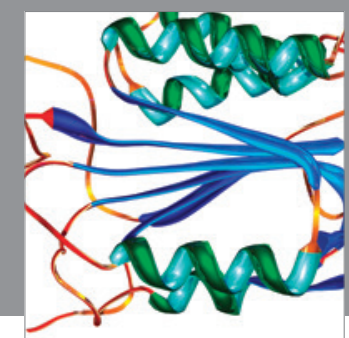

Disease Markers
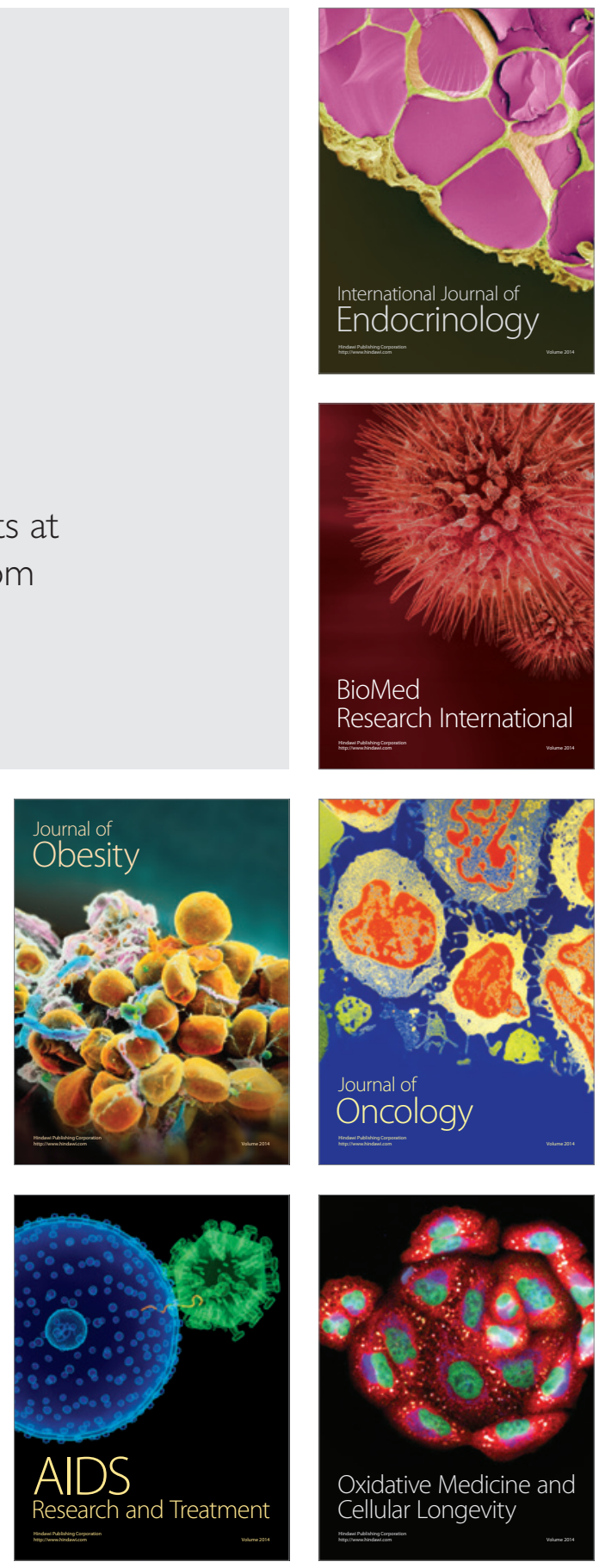